\title{
Art in the Digital during and after Covid: Aura and Apparatus of Online Exhibitions
}

\author{
João Pedro Amorim ${ }^{1} \&$ Luís Teixeira ${ }^{2}$ \\ ${ }^{1}$ Universidade Católica Portuguesa, School of Arts, CCD/CITAR, pamorim@porto.ucp.pt, \\ https://orcid.org/oooo-00o2-0267-1276 \\ ${ }^{2}$ Universidade Católica Portuguesa, School of Arts, CCD/CITAR, lteixeira@porto.ucp.pt, \\ https://orcid.org/oooo-00o2-1206-4576
}

\begin{abstract}
The public health measures that were put in place to contain COVID-19 impacted the lives of people and institutions alike. For its global impact and transformation, the pandemic has the potential to be classified as a mega-event. Such radical events have become great opportunities to the testing of new technologies and forms of organisation, (Masi, 2016) that might in the future become prevalent. The impact of the pandemic was particularly felt in the contemporary art world, as the entire cultural activity was suspended. During this period, art institutions and collectives around the world reacted by adapting and providing alternative materials online. This paper aims at reflecting upon the challenges facing the exhibition of contemporary art online. Following Boris Groys' (2016) actualisation of Walter Benjamin, we problematise how the digital reproduction of art affects the aura of an artwork. Proposing a critique of the apparatus of digital platforms, we analyse how the digital reproduces and enhances ideological structures that overpass the whole of society. For that purpose we analyse how four different organisations (an artist-run space, an art gallery, a museum and an art biennale) have migrated their activity to online platforms. The casestudies will allow a broad understanding of the different approaches available - with some radically taking advantage of the digital environment, and others merely digitising the role taken henceforth by printed catalogues.
\end{abstract}

Keywords: reproducibility of the work of art, Art in the Digital, Aura, Contemporary Art, apparatus

Slavoj Žižek (2014) describes an event as the "manifestation of a circular structure in which the evental effect retroactively determines its causes or reasons," (p. 13) an extraordinary happening with a "miraculous effect," something that disturbs the existing epistemologies hence creating new orders of the possible. We claim that COVID-19 is evental and, given its global and massive impact, that it can be classified as a mega-event. Several countries around the world implemented legislation that redefined the limits of everyday life. As all non-essential physical public activities were discouraged or forbidden altogether, we witnessed a steep increase in digital activity and the emergence of new or unknown virtual tools, frameworks and environments. For Masi (2016), a mega-event is "the ideal land to test not only technologies, but an entire vital system that overlaps and replaces the pre-existent world," (p. 47) i.e. testing new habits that can shape new economies and information systems. The most evident example is the rise of the platform Zoom that had around 10 million daily users in December 2019, and has grown to 300 million global users by the

(C) AesthetixMS 2020. This Open Access article is published under a Creative Commons Attribution Non-Commercial 4.o International License (http://creativecommons.org/licenses/by-nc/4.o/), which permits non-commercial re-use, distribution, and reproduction in any medium, provided the original work is properly cited. For citation use the DOI. For commercial re-use, please contact editor@rupkatha.com. 
end of April. ${ }^{\mathrm{i}}$ Online videoconference services have been available since the 2000 , but Zoom provided the best mainstream answer to the specific needs created by the pandemic.

Art and culture are amongst the most affected activities by the pandemic, as museums closed, cinemas were emptied, concerts were cancelled. Some art forms have easily adapted to the digital - e.g. cinema and music - even if such online formats don't replace the experience of live events and film screenings, and if that raises several questions about the economic sustainability of artists and industry. Contemporary art on the other hand faces more complex challenges to provide digital alternatives for experiencing exhibitions or artworks, in particular if we consider the most traditional media of painting and sculpture. The technological infrastructure and acquaintance to reproduce exhibitions digitally has been available, even if not evenly, for some years. But the high costs involved, the fear of losing visitors and the attachment to auratic and presential experiences of art has been, if not an impediment, a retardant. The mass closure of art venues prompted many institutions to invest more in their online presence. The desire to engage with their audiences and the fact that our current economy of visibility is based on quantitative evaluation - number of visitors, number of views, etc - and punishes inactivity and silence, pushed many actors to repurpose their activity for digital presentation.

If for many the transition was temporary, the scale and duration of the COVID-19 megaevent forecasts an acceleration of the spreading of online exhibitions from the specialised disciplines (e.g. Digital Art) and major institutions to reach a wider group of agents. As we might be in the verge of a new attitude towards art in the digital, it's relevant to analyse how the aura of a work of art is altered by its digital reproducibility, as well as critically questioning how the available apparatuses mediate the artistic experience. This paper reviews how institutions of different typologies and with different approaches adapted (or not) to this situation: an artist-run space (Dentro), a commercial gallery (KOW Gallery), a museum (Tate Modern) and a biennial (Biennale of Sydney).

\section{The Digital Reproducibility of the Work of Art}

Writing when mechanical technologies of reproduction were massively spreading, Walter Benjamin (1939/2000) understood that even "the most perfect reproduction will always lack one thing: the here and now of the work of art - the unity of its existence to the place where it is" or "what we call its authenticity" ii (p. 273). Such is the aura of a work of art, its link to tradition, bringing to the present experience its "material duration" and its "capability of historic testimony." (Benjamin, 1939/2000, p. 275) The mechanical reproduction operates an historical transformation of the human perception and of the function of art by causing a decline of the aura. The work of art becomes independent of what it inherits from its ritual and cultual lineage. (Benjamin, 1939/2000, p. 281) Photography and cinema artworks are made to be reproducible, there are no originals, only series of copies. The copy is "virtual, siteless, ahistorical." (Groys, 2016, p. 139) For the first time works of art were made accessible and widely available for massconsumption, shifting the function of art from a ritual to a political purpose. (Benjamin, 1939/2000, p. 282)

Digital reproduction consists in the multiplication of digital files, invisible digital data. "The digital image is an effect of the visualisation of the invisible image file" that is "always staged or performed." (Groys, 2016, p. 143) Whereas a mechanical reproduction exists through time, each presentation of the digital reproduction consists in a new momentary interpretation of the data in the image file, processed through an always different set of hardware and software. As "every act 
of visualisation of digital data remains uncertain in its relationship to the original, [...] every digital copy has its own 'here and now' - an aura of originality." (Groys, 2016, p. 144)

Moreover, in each presentation there is a supplementary reproduction - the reproduction of the user. (Groys, 2016, p. 145) All our digital actions are tracked and registered in databases with the user being unaware of the role he plays in "acts of self-traceability." (Stiegler, 2018, p. 173) The digital experience consists in the simultaneous reception and emission of information: the "screenification of writing." (Stiegler, 2018, p. 173) It is a pharmakon: simultaneously poison "enacted through the mediation of the fully computational and automated system"; and remedy, as an opportunity to create a new critical space "through a completely rethought hermeneutics." (Stiegler, 2018, p. 173) The digital condition is defined by its algorithmicity, ${ }^{\text {iii }}$ i.e. the "automated decision-making processes" that try to interpret the massive quantity of information produced and stored digitally, (Stalder, 2018, p. 6) hence delegating "analytical functions of the understanding to computational automatisms.” (Stiegler, 2018, p. 176)

The development of the digital has always been a terrain disputed by industry against digital communities and activists who try to circumvent the authoritarian structures established by the former - e.g. software copyright and the lack of transparency of the programming behind it. Companies create increasingly immersive platforms to maximise the collection of data that is later sold to advertisers. According to McLuhan, media are a "constitutive element of reality [...] that codetermine our personal relation to and behaviour in the world." (Stalder, 2018, pp. 43-44) As the time spent online worldwide increases, ${ }^{\text {iv }}$ the world that we live in is increasingly more defined by the structures of digital capitalism. This ultimately results in the decay of attention (Stiegler, 2018). ${ }^{\mathrm{v}}$

\section{Tate Modern}

Tate Modern is a contemporary and modern art museum located in London and was the most visited museum in the United Kingdom in 2018 with 5,9 million visitors. Tate Modern had already a strong digital presence even before COVID-19 struck. Their website has a wide range of multimedia materials. Throughout the years, across their platforms they shared audiovisual essays, documentation videos and photographs, articles for further reading, podcasts, interviews, $360^{\circ}$ video guided tours and other contents. Before their closure - that lasted from mid-March until July 27th -, Tate Modern had four ongoing temporary exhibitions by Kara Walker, Steve McQueen, Andy Wahrol and Dóra Maurer, all of which were extended.

While the other exhibition pages feature the common materials you'd find in other exhibitions in Tate Modern, Kara Walker's monumental sculpture presented on the Turbine Hall, Fons Americanus, is presented with a comprehensive multimedia dossier. However, it was already available before the closure. Under the title "Look Closer", the dossier minutiously details the allegories and the representation of each one of the figures that compose the statue, illustrated with general, close-up and detail photographs. The curatorial text as they delves into the contexts from which it emerged, linking it to other works in the history of art. The page features an audiovisual essay documenting the process of creation of the work, with the participation of the artist.

The materials provided illustrate only partially the work. Besides, as the Turbine Hall has been built to host artworks with massive dimensions - Fons Americanus is 13 metres high -, the materials are probably meant to foster interest and curiosity in an experience greatly dependent on the subjective perspective of scale. 


\section{Biennale of Sydney}

The Biennale of Sydney opened on March 14th and closed one week later. Displayed across several venues were more than 700 works by 101 artists. The shut-down was announced along with the news that the Biennale had teamed up with Google Arts and Culture to move all the exhibitions online. The digital programme features 30 online exhibitions dedicated to specific artists, plus 7 exhibitions of the venues.

Each exhibition consists of a dynamic scroll-down page where you can navigate through a range of different media that provide different levels of access to the exhibition. There are exhibition views, video documentation, textual information (ranging from declarations of the artist to curatorial texts), some video works have excerpts available, audio recordings of artist talks, links to extensive reading and $360^{\circ}$ virtual navigation in most of the rooms. For example, the online exhibition for Ibrahim Mahama "No Friend But the Mountains", opens with a documentation video of the massive installation. As you scroll down, a photo of the artist appears with his biographic note, followed by descriptions of his artistic practice. It is followed by a high definition photography of the installation and short curatorial texts. As you continue, the image zooms to different details of the image. At the end of the page you can navigate in $360^{\circ}$ inside this and other rooms of the venue.

In general, the online Biennale of Sydney provides a diverse and complete way to access the works and the exhibitions, allowing you to navigate around it - as freely as technology allows. They articulate different media in order to reproduce in the most appropriate way the experience of each art work. Even though the technology cannot grasp some properties of the exhibitions (textures, materiality and subjective impression of scale) it is an attempt to completely reproduce the original exhibition. It is to be noted that some time-based media are not displayed in their entirety - only featuring photographs or excerpts.

\section{KOW Gallery}

KOW's portfolio gathers a diverse range of artists that work closely with socially engaged art. Based in Berlin, they offer a program of exhibitions where you can find artworks that range from complex installations, to video-art and films, archival practices and process-based collective works. Opened in 2009 in a building "constructed on the ruins of a failed investment from the early 1990s", where they stayed until 2019, "the gallery's exhibitions as well as its curatorial formats and publications aim to address a broad international public."vi

From April the 7 th to May 31st, KOW presented on their website the virtual exhibition "The Illusion of a Crowd," by Clemens von Wedemeyer. Comprising a curatorial text by Alexander Koch, 5 full video-works by the artist, and 5 exhibition views of the video-installation, the exhibition allowed full access to all the videos. As cinema and video-art are two-dimensional artforms, an exhibition of such media can be presented on the interfaces that are broadly available today - smartphones, computers and other screens. "The Illusion of a Crowd" is therefore a complete online exhibition, adapted to the devices where it is played.

The choice of the exhibition is also paradigmatic "The Illusion of a Crowd" sees Clemens von Wedemeyer, an artist and professor in HGB Leipzig interested in the modes of production of images and the study of collective actions, questioning "What distinguishes digital hordes from physical ones? And how is the individual human being part of a crowd, or many crowds, even in isolation?"vii 


\section{Dentro}

Dentro is an artist-run space in Porto, Portugal. In March 14th they cancelled the programme of exhibitions for 2020. As an alternative, they invited artists to the programme "Conter" (to contain). This project was created due to the limitations of social isolation and because of the desire of "maintain[ing] the contact within the artistic community," viii as well as to provide a platform for artistic activity. The invited artists received a set of photos and videos of the empty gallery - templates -, where they were asked to digitally edit their work onto. The artists were free to keep a realistic presentation as a simulation of an actual exhibition, or to take this chance to create virtual experiences that would be impossible to experience otherwise. The videos were presented on their Facebook and Instagram pages. ${ }^{\text {ix }}$

From April to July 2020, 36 virtual exhibitions were held. While some of the presentations can be classified as reproductions of exhibitions that could have happened - that is, following the rules of the physical world - others played with the vast possibilities of virtuality. Some took the opportunity to present artworks that defied the laws of physic, namely gravity; others blended the photos of the exhibition space with their own photos creating a new spatial virtuality (See Figure 1); others added virtual artefacts, like abstract ${ }_{3} \mathrm{D}$ animations; one artist used this chance to transform the gallery in an animated sculpture with moving walls; yet others, worked with the photographs of the exhibition space as a matter, decomposing them as ASCII (See Figure 2), or giving them a pictorial quality, hence bringing the template to become part of the work of art (See Figure 3).

The results are natively digital exhibitions. When templates of the gallery become elements of a new original work, they challenge the indexical nature of the template, transforming the reproduced background into an integral part of the digital artwork. When they are the stage of a new reality - inexistent in the physical - they fully assume their virtuality. In both cases, the templates lose their reference to the space they reproduce.

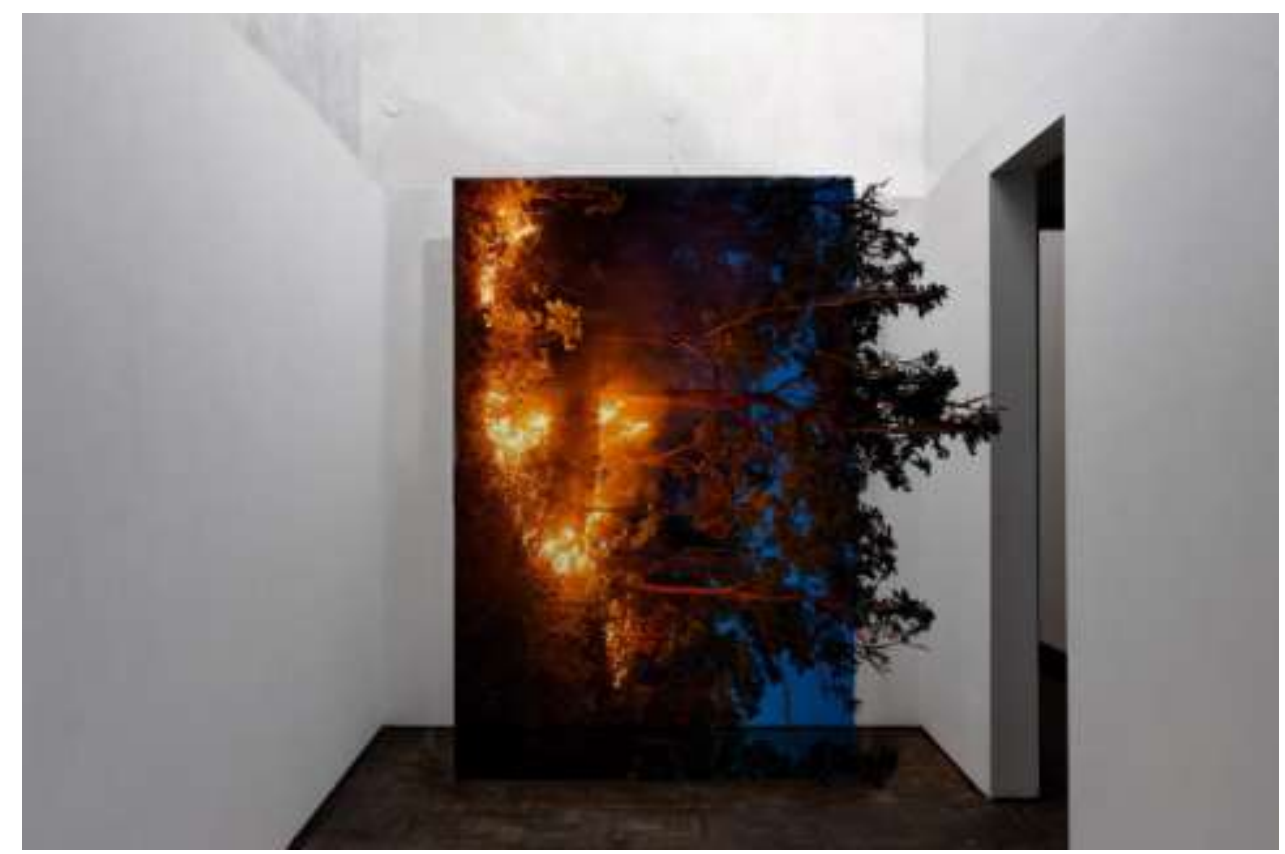

Figure 1: THAT NATURE IS A HERACLITEAN FIRE,AND OF THE COMFORT OF THE RESURRECTION (DA NATUREZA, FOGO HERACLITIANO, E DO CONFORTO DA RESSURREIÇÃO) by João Sarmento @ Dentro 
6 | Rupkatha Journal, Vol. 12, No. 5, 2020
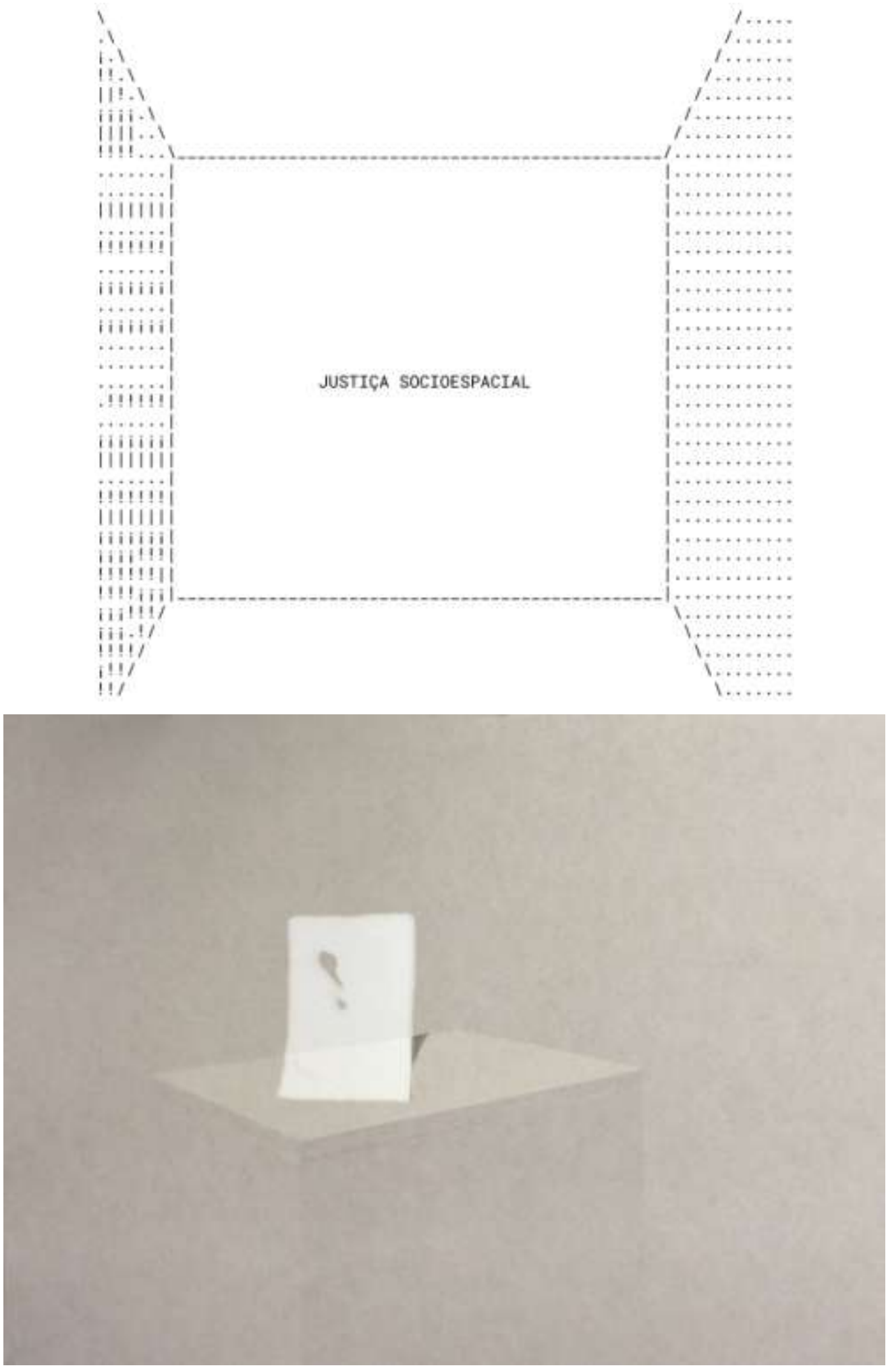

Figure 2: "\$€€€" - do ciático à ponta dos dedos by Gaspar Cohen $\odot$ Dentro

Figure 3: 5-7-5, by Rita de Almeida Leite @ Dentro 


\section{The challenges of Art in the Digital}

The presentation of artworks and exhibitions online can be characterised within a spectrum that goes from a reproduction of an actual physical exhibition (Biennale of Sydney) - in which case even if the digital experience can have an aura of its own, it doesn't replace the missing aura of the actual works and space - to a fully original, authentic and auratic experience (KOW), even if it's built upon physical references (Dentro). While the presentation of traditional media like painting and sculpture is only complete when it happens physically; disciplines such as Digital Art, Cinema and Music can be completely experienced online. However, the boundaries are very easily crossed: the same way painters and sculptors presented original work in Dentro by using digital tools, many works classified as New Media Art involve materiality, site-specificity or bodily interaction.

The mainstream digital experience makes any form of aesthetic rupture difficult. A significant part of the experience is mediated by automatic algorithms that contain "all the biases, prejudices and ethnocentric judgements of those who produce them in the first place." (Sardar, 2020, p. 9) They are designed to be addictive and create a false feeling of complete knowledge, hence making it difficult to overcome forms of ignorance we are incapable of thinking about because "they are out of the framework of the dominant paradigms." (Sardar, 2020, p. 9) The data economy "reinforces current trends, amplifying our prejudices and pushes us towards disturbing futures," (Sardar, 2020, p. 7) setting a "smog of ignorance" as the background of our consciousness.

Stimuli in the physical world are not so pervasive. Moreover, the architecture of museums and galleries stages a ritual of entrance that creates a rupture with what came before, thus enhancing the cognitive and sensitive ability of the visitor towards the artistic experience. Digital platforms cannot reproduce this. We reach all these online exhibitions after a series of clicks or actions. With its accessibility and instantaneity, the experience of art in the digital easily becomes distracted and superficial. The digital condition favours multitasking and constant interconnectedness, thus installing in our consciousness an uninterrupted state of alert that prevents contemplation. (Han, 2014) Our desires are guided by a series of automations that define the digital and our own consciousness, hindering more meaningful artistic experiences.

Finally, while in previous regimes of representation the artistic dimension of a work of art was second to a ritualistic or religious function (Benjamin, 1939/2000, p. 281), in the digital the work of art is before anything else content that feeds the needs of the data economy.

If the mainstream digital environment prevents "not only thinking but even the cultivation of the possibility of thinking," (Stiegler, 2018, p. 175) it becomes necessary "a political alternative" that faces the entropy of big data by "dis-automatiz[ing] the implementation of rules of certification." (Stiegler, 2018, p. 178) The challenge of the art community is to create artistic experiences that can reveal or counter the digital apparatuses, and find ways of reclaiming the autonomy of art against the data economy.

\section{Funding Disclosure}

This article is a result of the project NORTE-01-0145-FEDER-022133, supported by Norte Portugal Regional Operational Programme (NORTE 2020), under the PORTUGAL 2020 Partnership Agreement, through the European Regional Development Fund (ERDF). This publication is 
sponsored by National Funds through FTC - Foundation for Science and Technology under the project UIDB/oo622/2020.

\section{Notes}

iSource: https://www.theverge.com/2020/4/23/21232401/zoom-30o-million-users-growth-coronaviruspandemic-security-privacy-concerns-response. Accessed: 28th May 2020.

${ }^{\text {ii }}$ All translations from French and Italian have been made by the authors of the article.

iii The other two fundamental features are referentiality and communality (Stalder, 2018).

${ }^{\text {iv }}$ Source: https://www.statista.com/statistics/319732/daily-time-spent-online-device/. Accessed: August 1oth 2020.

${ }^{\mathrm{v}}$ See more: Stiegler (2018, pp.154-171).

${ }^{v i}$ Source: https://www.kow-berlin.com/about. Accessed: July 2 oth 2020.

vii The exhibition is still available here: .

${ }^{\text {viii }}$ As stated in the invitation email Dentro sent to artists.

${ }^{\text {ix }}$ See https://www.facebook.com/DENTRo/ or https://www.instagram.com/na_dentro/.https://www.kowberlin.com/exhibitions/illusion-einer-menschenmenge

\section{References}

Benjamin, W. (200o). L'oeuvre d'art à l'époque de sa reproductibilité technique (M. Gandillac, R. Rochlitz, P. Rusch, Trans.). Oeuvres: Tome III. Éditions Gallimard. (Original work published 1939)

Groys, B. (2016). In the flow. Verso.

Han, B.C. (2014). A Sociedade do Cansaço (G. L. Encarnação, Trans.). Relógio D'Água. (Original work published 2010)

Masi, E. (2016). Impatto pedagogico e sociale dei grandi eventi [Doctoral dissertation, University of Bologna]. http://doi.org/10.6092/unibo/amsdottorato/7504.

Sardar, Z. (2020). The smog of ignorance: Knowledge and wisdom in postnormal times. Futures, 120. https://doi.org/10.1016/j.futures.2020.102554.

Stalder, F. (2018). The digital condition (V. A. Pakis, Trans.). Polity Press. (Original work published 2016)

Stiegler, B. (2018). The neganthropocene (D. Ross, Ed., Trans.). Open Humanities Press.

Žižek, S. (2014). Event: A philosophical journey through a concept [eBook edition]. Melville Books.

João Pedro Amorim is a visual artist, PhD candidate and a research fellow at the Digital Creativity Centre, School of Arts, Universidade Católica Portuguesa. He holds a Master in Contemporary Artistic Practices and a Bachelor in Communication Sciences.

Luís Teixeira is a Professor and member of the direction at the School of Arts, Universidade Católica Portuguesa, Executive Coordinator of the Master in Management of Creative Industries. He holds a PhD in Electrotechnical and Computer Engineering. 